\title{
Approximate mechanical behavior analysis of a thick-wall metallic liner reinforced with composites, submitted to internal pressure
}

\author{
E. VARGAS-ROJAS ${ }^{1 *}$, C. PALACIOS-MONTÚFAR ${ }^{2}$, H. HERNÁNDEZ-MORENO ${ }^{1}$, \\ and J.L. GONZÁLEZ-VELÁZQUEZ ${ }^{3}$ \\ ${ }^{1}$ IPN-ESIME Ticomán, Ave. Ticomán 600, Col. San José Ticomán, México D.F. 07340 \\ ${ }^{2}$ IPN-ESIME Zacatenco. Edificio Z4, $2^{\circ}$ Piso. Ave. IPN s/n Col. Zacatenco, México, D.F. 07738 \\ ${ }^{3}$ IPN-ESIQIE. Edificio 8, IPN s/n Col. Zacatenco, México, D.F. 07738
}

\begin{abstract}
This study aims to simulate and to analyze the elastic and the damage behavior of a reinforced metallic liner (RML) by means of a computational tool, in order to aid in the design of high specific-stiffness and -strength barrels for heavy-duty hydraulic applications. Case studies for the program validation are undertaken using an AISI 1026 or St52.3 steel tubing reinforced with a polymeric composite of glass fiber and epoxy resin, wound in a hoop pattern. The mechanical behavior of the RML under internal pressure with no-end effects is predicted by means of strain measurements at the outermost layer. The mathematical model is based on the Classical Lamination Theory (CLT) improved with kinematic relationships that allow to introduce curvature effects. Numerical results based on experimental measurements show that the reinforcement is effective, allowing to considerably augment the maximum bearable pressure with respect to a non-reinforced metallic liner (nRML), without important weight or cost increase.
\end{abstract}

Key words: mechanical behavior analysis, thick-wall metallic liner, composites, internal pressure.

\section{Nomenclature}

\begin{aligned}$A & -$ axial, \\ $c & -$ cos $\theta \\ , \mathrm{C} & -$ compression, \\ $\mathrm{CLT} & -$ Classical Lamination Theory, \\ $\mathrm{cV} & -$ coefficient of variation, \\ $\mathrm{D} & -$ dimension, \\ $\mathrm{e} & -$ outer, \\ $E & -$ elastic modulus, \\ $f & -$ fiber, \\ $f_{i}, f_{i j} & -$ strength tensors or Tsai-Wu coefficients, \\ $\mathrm{FPFA} & -$ First Ply Failure Approach, \\ $F_{1,2} & -$ strength parameters of a lamina, \\ $F_{1 t} & -$ longitudinal tensile strength of a lamina, \\ $F_{2 t} & -$ transverse tensile strength of a lamina, \\ $F_{1 c} & -$ longitudinal compressive strength of a lamina, \\ $F_{2 c} & -$ transverse compressive strength of a lamina, \\ $F_{6} & -$ in-plane shear strength of a lamina, \\ $G & -$ shear modulus, \\ $\mathrm{G}-\mathrm{Ep} & -$ glass-epoxy reinforcement, \\ $H & -$ hoop, \\ $i & -$ inner, \\ $m & -$ mass, \\ $m & -$ (subscript) matrix, \\ $M & -$ mass fraction, \\ $m e t & -$ subscript) metallic tubing, \\ $\mathrm{nRML} & -$ non-Reinforced Metallic Liner, \\ \hline $\mathrm{N} & -\end{aligned}$

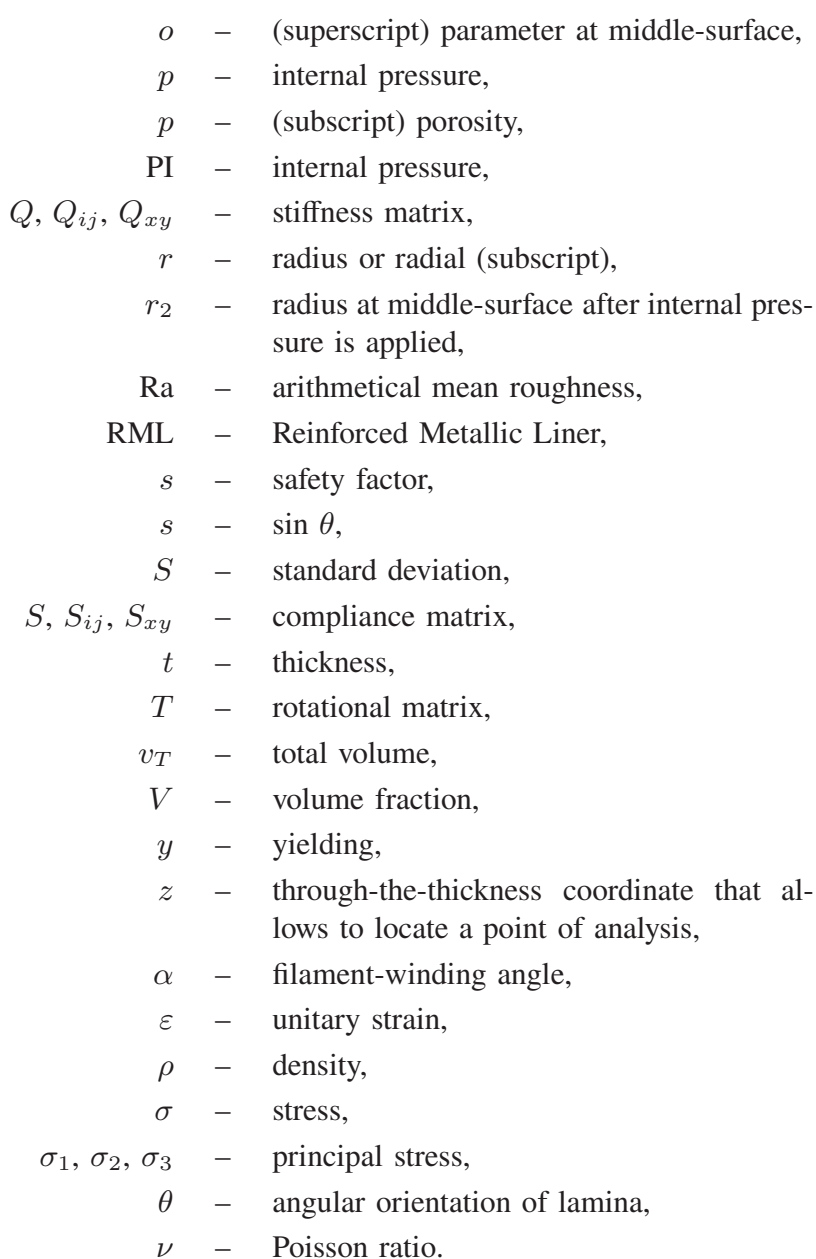

\footnotetext{
*e-mail: 3rikvargasrojas@gmail.com
} 


\section{E. Vargas-Rojas, C. Palacios-Montúfar, H. Hernández-Moreno, and J.L. González-Velázquez}

\section{Introduction}

According to Franzinger in [1], heavy-duty hydraulic components will continue to see higher pressures as they become lighter and more compact. Competitive pressures from alternate technologies continue to require increments of power-toweight and power-to-volume ratios. Increments of the operating pressure will continue until other restrictions on component size such as rod buckling, or manufacturing requirements become the limiting criteria. Higher operating pressures would be affordable, estimating them to reach the 69 to $138 \mathrm{MPa}$ (10 to $20 \mathrm{ksi}$ ) range. This must be accompanied by strong, lightweight composites or other types of materials that ensure safe, reliable, and energy-efficient systems. To bear these high pressure ranges, the thickness of metallic steel tubing could be increased, so as well as weight and cost. For this reason a composite-reinforced metal barrel is developed aiming to augment its specific mechanical properties taking advantage of the properties of a composite reinforcement of this kind like resistance, light weight, and lower costs with respect to a thicker metallic section. The reinforcement is wound in the hoop direction of the metallic tubing using continuous fiber glass roving impregnated with epoxy resin (i.e., a G-Ep composite). Moreover, continuous filaments of this kind are the cheapest and strongest forms of fiber reinforcement. Industrial applications of this metal-lined, filament-wound pressure tubing include hydraulic power applications, heavy-duty hydraulic cylinders, pipeline reinforcement, and antiballistic armoring.

Within a polymeric composite material reinforced with ceramic fibers, the latter can be oriented to match the direction and magnitude of stresses in a structure. According to Shen in [2], filament wound products are produced using any of the three basic types of winding patterns: polar, helical, or hoop. In hoop winding, the fiber is deposited close to $90^{\circ}$ with respect to the longitudinal axis -i.e., along the direction of principal stresses in an internal pressure test with no end effects-. In the case of this research, the hoop pattern is chosen considering the shape of the part under study, and the required reinforcement orientations of a uniaxial internal pressure testing.

Furthermore, the performance of a composite structure is influenced by its environmental history, temperature and moisture distributions, processing and hygrothermal stresses [3]. Nevertheless, the traditional analytical procedures do not take into account neither the initial state of stress of the material due to curing nor the effects of curvature. In this sense, the fabrication process of the G-Ep reinforcement may introduce initial stresses due to the thermal cycle. Thus, thick sectioned structures tend to generate residual stresses which mostly deteriorate the structural performance [4]. The effects of curvature and the initial state of stress rest unknown for our G-Ep reinforcement. However, in order to minimize some uncertainties, the effects of curvature are taken into account by means of kinematic relationships. The objective of this work is thereof to predict the mechanical behavior within the elastic region, as well as to predict initial and subsequent fail- ure of the polymeric-composite reinforcement of the RML. In order to do so, a computational tool with the CLT as basis (cf. Appendix A) is written using Matlab ${ }^{\circledR}$ software, and then corroborated with mechanical-characterization tests.

Material under study is a metallic liner fabricated with an AISI 1026 or St52.3, medium-carbon steel (C, 0.27\%; Mn, $0.81 \%$; Si, $0.20 \%$; P, $0.01 \% ; \mathrm{S}, 0.02 \%$ ), reinforced with a polymeric composite of glass fiber and epoxy resin, entirely wound in a hoop pattern. With a design motivation of reinforced metallic barrels in mind, intending to explore the effect of different through-the-thickness dimensions, and searching into a robust validation of the numerical tool, then two ratios between the reinforcement and the metallic wall thicknesses are considered. In line with the preceding idea, experimental data comprising constituent volume fractions of the composite reinforcement, engineering constants of the epoxy matrix, and strain measurements at the outermost layer of the RML are used as input data. The RML is mechanically characterized with two kinds of tests: internal pressure with no-end effects and axial compression. Taking into account the influence of the curvature of the structure under study, and that the strain measurements are made at the external surface of a thick-wall cylinder, kinematic relationships are introduced so the engineering constants of the RML can be calculated at the middle-surface of the wall of the reinforced material.

The outline of the document is detailed next. Section 2 deals with the setup of the experimental procedure, comprising the description of the constituent materials of the RML, the experiment and results. Section 3 is about the analytical procedure commonly used when dealing with orthotropic, layered structures on account of the CLT. Here a comparison between computed and experimental results is brought about. The safety factor of the RML and of nRML computed with the standard method are reported. Then, a non-standardized, expanded method is introduced searching to consider curvature effects. In consequence, the results previously computed with the CLT are recalculated and compared. Finally, a study on specific mechanical properties and costs is conducted.

\section{Experimental procedure}

2.1. Cylindrical test probes. An AISI 1026, unhoned, seamless, steel tubing is reinforced with 40 composite layers of E-type fiber glass roving and epoxy resin, overwrapped in a hoop pattern, as depicted in Fig. 1. This steel grade is one of the most common selections used for hydraulic jack barrels according with [5]. As the G-Ep reinforcement has the same orientation as the reference axis directed along the hoop direction, the layers orientation angle is $0^{\circ}$ (observe that the filament-winding angle $\alpha$ is $90^{\circ}$, i.e. the angle of the fiber roving with respect to a generator of the surface at a local point). Thereof, this lay-up can be locally designated as $\left[0^{\circ}\right]_{40}$, which represents a symmetric and regular laminate in which layer number one is the innermost. Laminate thickness is $5.08 \mathrm{~mm}$ which stands for 40 plies, each one with a thickness of $0.127 \mathrm{~mm}$. Reinforcement is commercial glass-fiber roving type 30 whose mechanical properties are taken from 
literature, [6]: elastic modulus, $74 \mathrm{GPa}$; shear elastic modulus, $30 \mathrm{GPa}$ and Poisson ratio, 0.25; density, $2600 \mathrm{~kg} / \mathrm{m}^{3}$. Matrix is commercial epoxy resin with density reported equal to $1200 \mathrm{~kg} / \mathrm{m}^{3}$ [6].

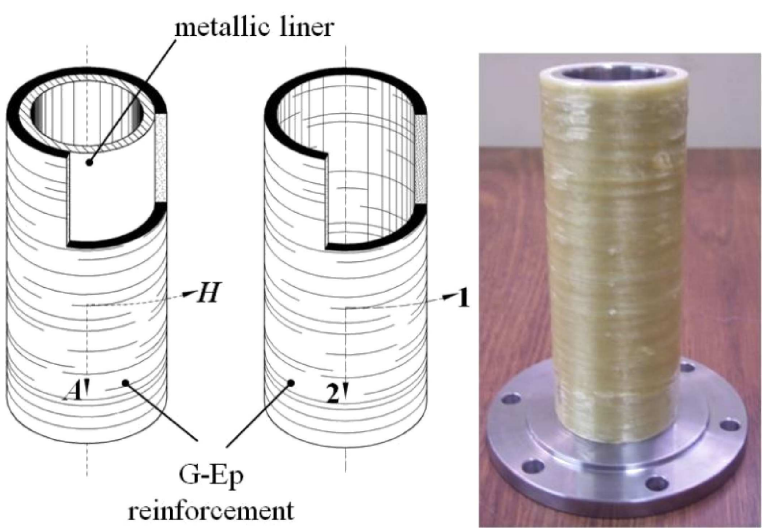

Fig. 1. RML and G-Ep reinforcement with reference system

Prior to its covering, the outer surface of the steel tube is improved by sanding. Once a long steel tube is fully wrapped, it is cut into shorter segments and their internal diameters are machined to two different thicknesses from a very smooth surface finish near the ends ( $\mathrm{Ra} 0.4 \mu \mathrm{m}$ ) to a rougher texture at mid-length $(\mathrm{Ra} 6.3 \mu \mathrm{m})$. In virtue of the high internal pressure intended to use to mechanically characterize the nRML and the RML material, a non-standardized testing device is developed. Its rubber seals located at the ends of the internal diameter of the test probes require high-quality surface smoothness, an aspect that considerably increases manufacturing costs. This machining operation of the RML represents a challenge as well.

In virtue of the latter, there are two kinds of test probes with different metallic wall thickness but with the same GEp reinforcement. In this document, internal pressure test probes are labeled as PI_1625 (thicker) or PI_1750 (thinner) after their inner diameter in thousands of an inch. Thus, the thicker test probes have the next dimensions and relationships: $\emptyset_{e} 60.16 \mathrm{~mm} \times \emptyset_{i} 41.28 \mathrm{~mm} \times 158.75 \mathrm{~mm}$, $t_{\text {met }}=4.36 \mathrm{~mm}, t_{\text {met }} / t_{G-E p}=0.9$; while the thinner test probes: $\varnothing_{e} 60.16 \mathrm{~mm} \times \varnothing_{i} 44.45 \mathrm{~mm} \times 158.75 \mathrm{~mm}$, $t_{\text {met }}=2.78 \mathrm{~mm}, t_{\text {met }} / t_{G-E p}=0.6$. In order to evaluate the effect of the reinforcement, a nRML with the following dimensions is tested under the same conditions: $\varnothing_{e} 50.01 \mathrm{~mm}$ $\times \emptyset_{i} 44.45 \mathrm{~mm} \times 158.75 \mathrm{~mm}$ that corresponds to the metallic liner of the thinner RML. Reinforced test probes accomplish the respective cylinders thick-wall criteria given by Shigley $\left(t / \varnothing_{i}<1 / 40\right)$, Dürr and Wachter $\left(t / \varnothing_{e}<1 / 10\right)$, and Gere and Timoshenko $(t / r<1 / 10)$.

2.2. Internal pressure characterization setup. The RML is mechanically characterized by means of an internal pressure test and a uniaxial compression test in order to measure the hoop and axial elastic modulus and the two Poisson ratios. Six reinforced tubes are tested under internal pressure up to $55.15 \mathrm{MPa}(8 \mathrm{ksi})$ and six under uniaxial compression up to $90 \mathrm{kN}$ (19850 pounds). Concerning the internal pressure test two devices are developed: a testing chamber and a pressure transducer as reported by author in [7]. Strains are measured using strain gages bonded at the outermost layer (up to four, three circumferentially- and one axially-oriented), and data is recorded with a System 6000 data acquisition unit from Micro-Measurements shown in Fig. 2. The internal pressure test probes are identified with their label, plus a consecutive number, plus an identification number of the strain gage bonded on its surface and its orientation, e.g., PI_1750-1(4H) stands for an internal pressure test probe with 1.750 " inner diameter; -1 , stands for its consecutive number; $4 \mathrm{H}$, represents the strain gage number 4 oriented in the hoop direction.

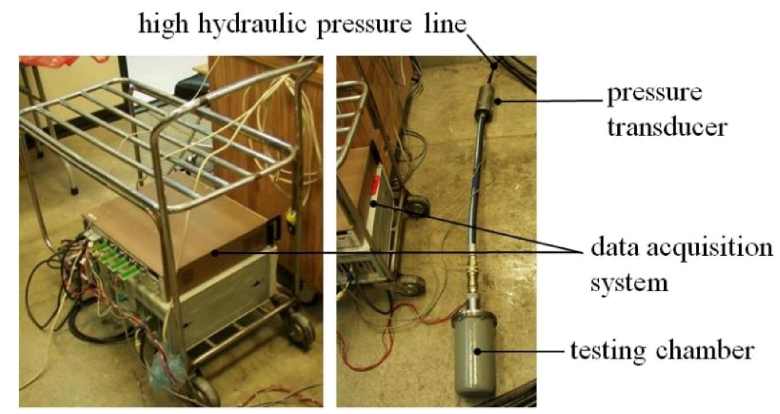

Fig. 2. Internal pressure test

2.3. Experimental results. Experimental data obtained from the internal pressure and compression mechanicalcharacterization tests of the RML are presented in Table 1. Internal pressure tests results are listed for each test probe, as well as their average, standard deviation and coefficient of variation. Compression results are included as a reference in order to verify that certain relationships accomplish as expected, like the equality between the elements $Q_{i j}=Q_{j i}$ of the stiffness matrix. The thinner compression test probes (C_1750) present high scattering on their engineering constants as computed from experimental data, therefore the test probe with the less variation in regard to the expected computed result is reported herein (C_1750_1, $\varepsilon>0.000333 \mathrm{~mm} / \mathrm{mm}$ ). However, the thicker test probes (C_1625) present low and acceptable rates of variation with respect to experimental results. Scattering in compression testing results is due to an unexpected lack of parallelism between the compression plates of the universal testing machine employed to conduct the tests.

Intending to predict the mechanical behavior of the RML starting with micromechanical relationships, the physical and mechanical properties of the constituent materials need to be known as well, such as the volume fractions, the density of the RML and of the G-Ep reinforcement, the elastic modulus of the matrix, and its tensile and compressive strength. All this data is experimentally obtained according to test standards and listed in Table 2.

In Table 3 each strength parameter is listed and the corresponding constituent material failure mode assumption is indicated. The respective lamina strength parameters $[F]_{1,2}$ serve as input data of the Hill-Tsai, Tsai-Wu, and FPFA failure models. The listed values are obtained by means of the micromechanical relationships reported in mechanics of composites literature [3, 13, 14]. 
E. Vargas-Rojas, C. Palacios-Montúfar, H. Hernández-Moreno, and J.L. González-Velázquez

Table 1

Engineering constants of the RML issued from internal pressure tests

\begin{tabular}{|c|c|c|c|c|c|c|}
\hline 1. & 2. & 3. & 4. & 5. & 6. & 7. \\
\hline Test Probes & Experimental & Numerical & Variation & Experimental & Numerical & Variation \\
\hline & \multicolumn{2}{|c|}{$E_{H}, \mathrm{MPa}$} & $\%$ & \multicolumn{2}{|c|}{$\nu_{H A}$} & $\%$ \\
\hline PI_1750_1 & 141088 & \multirow{4}{*}{92374} & 34.53 & 0.411 & \multirow{4}{*}{0.300} & 26.92 \\
\hline PI_1750_2 & 133555 & & 30.83 & 0.221 & & 35.81 \\
\hline PI_1750_3 & 122609 & & 24.66 & 0.365 & & 17.72 \\
\hline PI_1750 & 130743 & & 29.35 & 0.324 & & 7.49 \\
\hline$S$ & 12528 & - & - & 0.084 & - & - \\
\hline $\mathrm{cV}$ & $9.6 \%$ & - & - & $26 \%$ & - & - \\
\hline PI_1625_1 & 146727 & \multirow{4}{*}{110468} & 24.71 & 0.419 & \multirow{4}{*}{0.300} & 28.35 \\
\hline PI_1625_2 & 133555 & & 17.29 & 0.337 & & 11.08 \\
\hline PI_1625_3 & 126655 & & 12.78 & 0.319 & & 5.89 \\
\hline PI_1625 & 136288 & & 18.95 & 0.348 & & 13.89 \\
\hline$S$ & 10410 & & - & 0.045 & - & - \\
\hline \multirow[t]{2}{*}{$\mathrm{cv}$} & $7.6 \%$ & & - & $13 \%$ & - & - \\
\hline & \multicolumn{2}{|c|}{$E_{A}, \mathrm{MPa}$} & $\%$ & \multicolumn{2}{|c|}{$\nu_{A H}$} & $\%$ \\
\hline C_1750_1 & 76888 & 74925 & 3.37 & 0.289 & 0.243 & 15.73 \\
\hline$C_{-} 1625$ & 99444 & 96035 & 3.42 & 0.251 & 0.261 & 3.90 \\
\hline$S$ & 4867 & & - & 0.102 & - & - \\
\hline $\mathrm{cV}$ & $4.9 \%$ & & - & $40.5 \%$ & - & - \\
\hline
\end{tabular}

Table 2

Summary of physical properties experimentally obtained

\begin{tabular}{|c|c|c|c|c|}
\hline Property & Average & $S$ & $\mathrm{cv}$ & Standardized test method \\
\hline Fiber volume fraction, $V_{f}, \%$ & 43.8 & 0.80 & 1.83 & \multirow{3}{*}{$\begin{array}{l}\text { ASTM D } 2734-91,[8] \\
\text { ASTM D } 3800-90,[9]\end{array}$} \\
\hline Matrix volume fraction, $V_{m}, \%$ & 48.4 & 1.30 & 2.69 & \\
\hline Porosity volume fraction, $V_{p}, \%$ & 7.7 & 3.10 & 40.26 & \\
\hline G-Ep reinforcement density, $\mathrm{kg} / \mathrm{m}^{3}$ & 1700 & 0.01 & 0.65 & \multirow{2}{*}{ ASTM D $792-91,[10]$} \\
\hline RML density, $\mathrm{kg} / \mathrm{m}^{3}$ & 4700 & 0.14 & 3.00 & \\
\hline Matrix elastic modulus, $\mathrm{MPa}$ & 2423 & 498 & 20.54 & \multirow{2}{*}{ ASTM D $638-91,[11]$} \\
\hline Matrix tensile strength, $\mathrm{MPa}$ & 47.8 & 8.70 & 18.17 & \\
\hline Matrix compressive strength, $\mathrm{MPa}$ & 107.7 & 7.77 & 7.21 & ASTM D 695 - 91, [12] \\
\hline
\end{tabular}

Table 3

Summary of strength parameters of a basic lamina

\begin{tabular}{ccl}
\hline \hline Strength parameter & Value, MPa & Failure mode assumptions \\
\hline$F_{1 t}$ & 1095 & Composite with very stiff fibers, i.e., $E_{f} \gg E_{m}$. \\
\hline$F_{2 t}$ & 30.4 & $\begin{array}{l}\text { Linear elastic behavior to failure for the matrix. Residual stresses due to curing } \\
\text { are not taken into account. }\end{array}$ \\
\hline$F_{1 c}$ & 628.8 & Modeling of the matrix as an elastic, perfectly plastic material, [13]. \\
\hline$F_{2 c}$ & 68.6 & $\begin{array}{l}\text { The high compressive stress concentration at the interface, not taken into ac- } \\
\text { count, may cause compressive failure in the matrix and/or fiber crushing. }\end{array}$ \\
\hline$F_{6}$ & 23.9 & $\begin{array}{l}\text { The in-plane shear strength is the shear strength of the matrix, and according } \\
\text { to the Maximum-Shear-Stress Theory it is half of matrix tensile strength, [14]. }\end{array}$ \\
\hline
\end{tabular}

\section{Analytical procedure using the standard method}

3.1. Classical Lamination Theory, CLT. The engineering constants of the RML issued from experimental data are compared with computed values that are obtained with a routine written with Matlab ${ }^{\circledR}$ software, based on the CLT [3, 6, 13], expanded in Appendix A, and used for computations in Appendix B. CLT is based on the Kirchhoff hypothesis for plates and the Kirchhoff-Love hypothesis for thin shells, and is the
2-D analog of the ordinary 1-D beam theory assumption that sections normal to the beam axis remain plane after bending. Other hypotheses include that the normal stresses to the surface of the plate can be neglected; the constituent layers of the laminate are perfectly bonded; and the ultra thin adhesive layers between reinforcement layers should not distort under shear, as expounded in [3] and [15].

This routine predicts both plane stress and strain states of each G-Ep reinforcement layer. Damage behavior is simulated based on the Tsai-Wu, Hill-Tsai and FPFA failure criterions. 
Approximate mechanical behavior analysis of a thick-wall metallic liner reinforced...

The mechanical properties are recalculated for the remaining plies with a cyclic process until all plies fail, setting the failure point and the pressure rank for which the engineering constants are true. As presented by Daniel and Ishai in [3], and expanded on by author in [7], a flow chart for computation of safety factors and strength components of a general multidirectional laminate is shown in Fig. 3. The predicted engineering constants are calculated in the middle of the wall of the RML, at middle-surface. Input data includes physical and strength properties of the G-Ep reinforcement, ply orientation, number of plies, geometrical dimensions, mechanical loads, and a point of interest for analysis parameterized with $z$.
Results include the engineering constants of the G-Ep reinforcement and of the RML, the safety factor of the metallic ply and of each G-Ep reinforcement ply, and the overall material safety factor as well. This routine can be divided into four parts: the first one (step 1) determines the single lamina properties as a function of constituent materials properties. The second part (step 2 through step 8) determines the stiffness of each lamina and of the entire laminate. The third part (step 9 through step 16) calculates the strain and stress state for each lamina. Then, with these data gathered together, the fourth part (step 17 through step 23) determines the safety factors and margins of safety.

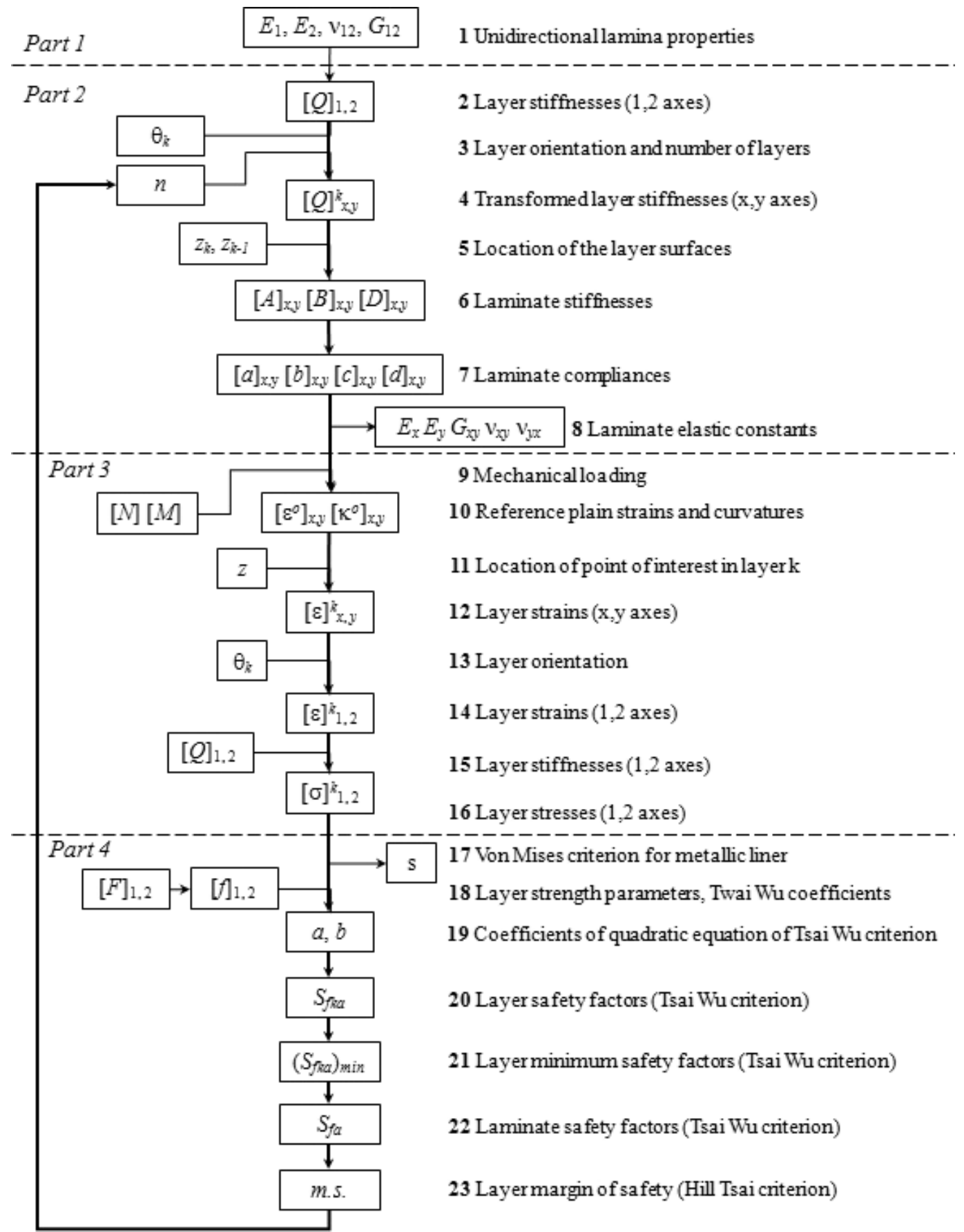

Fig. 3. Flow chart of the stress and failure analysis of multidirectional laminates using the CLT. After Daniel et Ishai, Ref. 3 
Once the failure of the first ply is reached, the pressure rank for which the first set of engineering constants are true, is set. Then, the mechanical properties of the RML are recalculated with a cyclic process until all plies fail. The number of the remaining plies $n$, is automatically re-entered at step 3 . As the laminate's orientation and mechanical properties remain the same, the procedure starting from step 4 is performed repeatedly until the remaining plies fail.

\subsection{Comparison of analytical results with experimental} data. In Table 1, the numerical results of the engineering constants of the RML (columns 3 and 6) are compared with respect to experimental ones (columns 2 and 5), thus the respective percentage of variation is indicated in columns 4 and 7, respectively. The reported experimental values are calculated from the acquired data using strain gages bonded at the outermost layer. Data of Table 1 listed in columns 2 and 5 correspond to average mechanical properties in virtue of the usage of several strain gages. Moreover, searching to corroborate the thick-wall cylinder criteria, the elastic modulus of the $\mathrm{nRML}$ is also experimentally obtained.

3.3. Safety factor of RML and nRML. In order to determine the safety factor via the state of stresses at each layer of the RML, strains need to be known. In Fig. 4, the measured strains in the hoop direction of one of the thinner test probes are plotted along the test pressure rank 0-41.4 MPa (0-6 ksi). The hoop strain at the outermost layer predicted with the standard method is plotted as well.

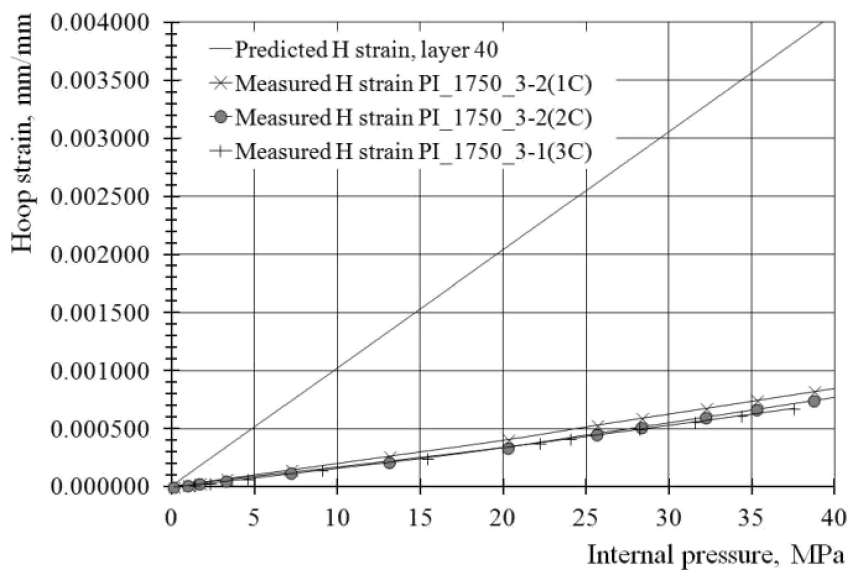

Fig. 4. Predicted and measured hoop strains at the outermost layer of thinner test probe PI_1750_3 assessed with the standard CLT method

Safety factors of RML and nRML are plotted in Fig. 5 as a function of the test pressure. As previously stated, both metallic layers have the same dimensions, the unique difference is the presence of G-Ep reinforcement in the RML. The safety factor of the G-Ep plies is calculated with the Tsai-Wu failure theory using, as input data, the engineering constants of a single ply computed in Appendix B with the aid of expressions (A12) and (A13). When the result is minor to one, then the ply fails. Thus, failure of the nRML is predicted to occur at $55 \mathrm{MPa}(550$ bar or $7.8 \mathrm{ksi}$ ) while the outermost layer of RML is expected to fail at $320 \mathrm{MPa}$ (3200 bar or $46.4 \mathrm{ksi}$ ), hence provoking a failure chain reaction of the remaining plies, the metallic one comprised. In order to visualize the influence of the G-Ep reinforcement on the resultant mechanical behavior of the RML, a plot of the safety factor of the nRML is also shown. The components of the state of stress in the main directions at the point of interest (radial, hoop, and axial) are calculated using Eqs. (1a), (1b), and (1c). The safety factor is determined with the Von Mises yield criterion, Eq. (A11).

$$
\begin{gathered}
\sigma_{r}=p r_{i}^{2}\left(1-r_{e}^{2} / r^{2}\right) /\left(r_{e}^{2}-r_{i}^{2}\right), \\
\sigma_{H}=p r_{i}^{2}\left(1+r_{e}^{2} / r^{2}\right) /\left(r_{e}^{2}-r_{i}^{2}\right), \\
\sigma_{A}=p r_{i}^{2} /\left(r_{e}^{2}-r_{i}^{2}\right) .
\end{gathered}
$$

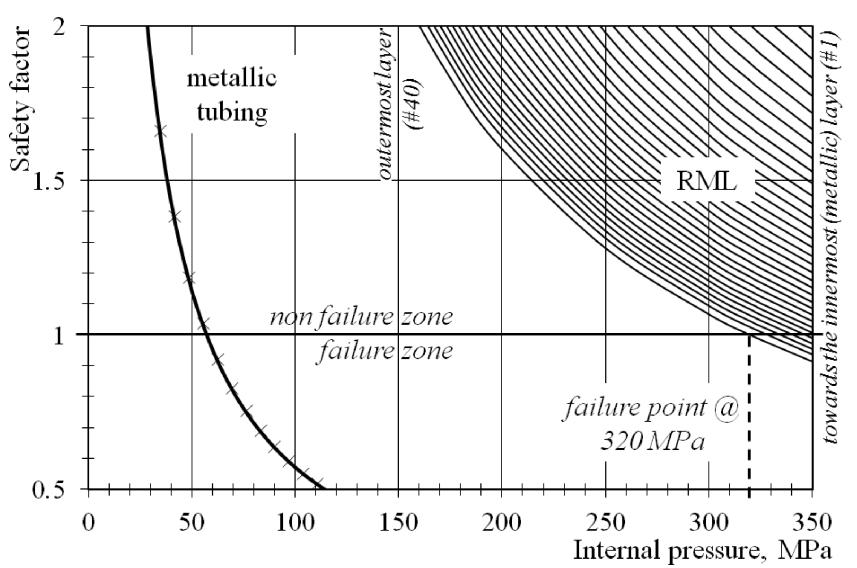

Fig. 5. Safety factor as a function of internal pressure of RML and nRML valuated with the standard CLT method. RML: $\emptyset_{e} 60.16 \mathrm{~mm}$ $\times \emptyset_{i} 44.45 \mathrm{~mm}$; nRML: $\emptyset_{e} 50.01 \mathrm{~mm} \times \emptyset_{i} 44.45 \mathrm{~mm}$. Metallic liners are the same indeed

3.4. Use of kinematic relationships. Looking into the curvature effects, a series of kinematic relationships are introduced in accordance with Fig. 6 and incorporated onto the standard method, so an improved method is proposed. In this sense, the

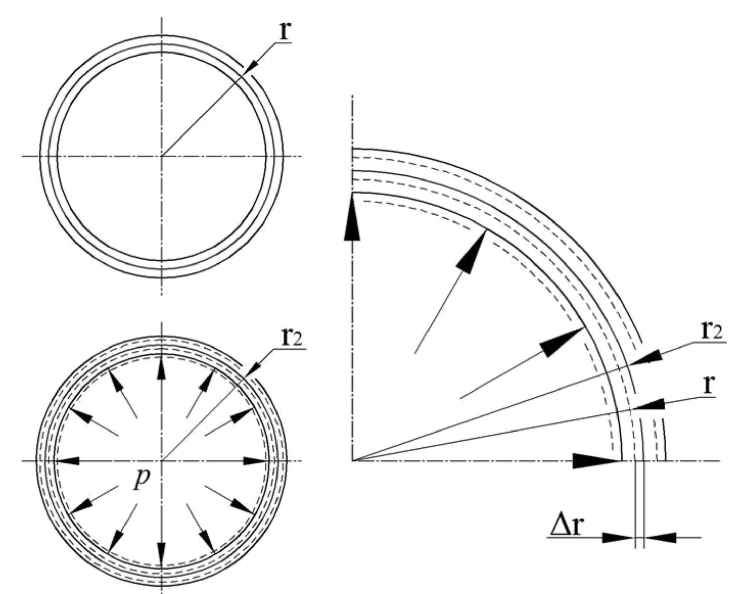

Fig. 6. Sectional view of the RML: before pressure is applied (top left); under internal pressure (bottom left); superposition of both states (right). In each case, dimension $r$ or $r_{2}$ stands for the radius of the middle-surface. Dotted lines represent the original state before pressure is applied 
Approximate mechanical behavior analysis of a thick-wall metallic liner reinforced...

procedure explained in Subsec. 3.1 and in Appendix A does not take into account the curvature of the cylindrical structure. Standard CLT only considers the input of the radius dimension when computing the external mechanical loadings (in Appendix A, step 9). The expanded method therefore, allows to calculate the engineering constants in the middle-surface of the laminate from the strain data acquired at the outermost surface, so the elastic constants of the RML can be accurately calculated, and the percentages of variation shown in the Table 1 adjusted.

The expressions of the hoop strain and curvature of an internal pressure test probe can be derived with the aid of Fig. 6 . The hoop strain in the middle of the thickness $\varepsilon_{H}^{o}$ is related to the change in circumference $\Delta(\pi D)$ before and after the internal pressure is applied, as stated by Eq. (2a). While the curvature at the middle-surface $\kappa^{o}$ is calculated using Eq. (2b), the hoop strain at any point of interest can be established with Eq. (2c) considering the through-the-thickness coordinate $z$ as the independent variable. Refer to the laminate reference axes previously depicted in Fig. 1. Expression (2c) is solved for the hoop strain at the outer radius with $z=t / 2$. This equation can be stated as a second degree order equation, (2d), and solved for $\Delta r$ when $z$ and $\varepsilon_{H}^{r e}$ are known. Then, the hoop strain at the middle-surface $\varepsilon_{H}^{o}$ can be calculated with expression (2e) and substituted onto expression (2f) so as to compute the desired hoop modulus $E_{H}^{o}$ at the middle-plane as a function of $r$. The same procedure is to be followed for the major Poisson ratio leading to Eq. $(2 \mathrm{~g})$. As previously stated, the non-end effect condition is considered, likewise the uniaxial state of stress that it induces. The procedure to compute the elastic constants at the middle-surface is illustrated in Fig. 7 and the evolution of the hoop modulus is shown in Fig. 8.

$$
\begin{gathered}
\varepsilon_{H}^{o}=\Delta(\pi D) / \pi D=\Delta D / D=\Delta r / r \\
\kappa^{o}=1 / r-1 / r_{2}=1 / r-1 /(r+\Delta r) \\
=-\Delta r /(r(r+\Delta r)), \\
\varepsilon_{H}^{r_{e}}=\varepsilon_{H}^{o}+z \kappa^{o}=(\Delta r / r)-(t \Delta r /(2 r(r+\Delta r))),
\end{gathered}
$$

$$
\begin{gathered}
\Delta r^{2}-\left(r\left(\varepsilon_{H}^{r_{e}}-1\right)+t / 2\right) \Delta r-r^{2} \varepsilon_{H}^{r_{e}}=0, \\
\varepsilon_{H}^{o}=\varepsilon_{H}^{r_{e}}+z \Delta r / r(r+\Delta r), \\
E_{H}^{o}=\sigma / \varepsilon_{H}^{o}=p r_{i}^{2}\left(1+r_{e}^{2} / r^{2}\right) /\left(r_{e}^{2}-r_{i}^{2}\right) \varepsilon_{H}^{o}, \\
\nu^{o}=\varepsilon_{A}^{o} / \varepsilon_{H}^{o} .
\end{gathered}
$$

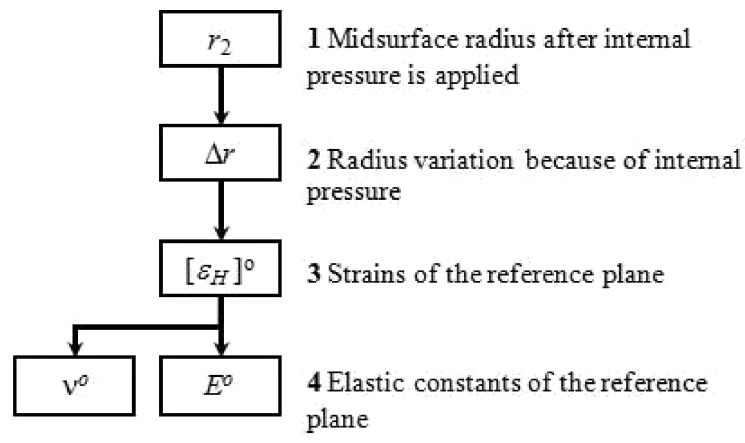

Fig. 7. Flow chart for the computation of the hoop modulus at the reference plain

The experimental data of the hoop strains of the thinner test probes as a function of internal pressure are processed and broken down in Table 4. All the internal pressure test probes are tested in their linear-elastic region, showing a highly linear behavior, therefore a linear regression can be established. The slope $m$, and the y-intercept $b$, are listed in column 2. Column 3 stands for the radius variation; column 4 lists the hoop elastic modulus at the outermost surface; column 5 presents the hoop elastic modulus at the reference plane; column 6 refers to the variation between the last two. Regarding the major Poisson ratio, column 7 notes it down at the middle-

\begin{tabular}{|c|c|c|c|c|c|c|c|c|c|}
\hline 1. & 2 & & 3. & 4. & 5. & 6. & 7. & 8. & 9. \\
\hline \multirow{3}{*}{ Test probe } & \multicolumn{2}{|c|}{$\sigma_{H}=m(p)+b$} & \multirow{2}{*}{$\Delta r \times 10^{-2}$} & \multirow{2}{*}{$E_{H}^{r e}$} & \multirow{2}{*}{$E_{H}^{o}$} & \multirow{2}{*}{ Variation } & \multirow{2}{*}{$\nu_{H A}^{O}$} & \multirow{2}{*}{$\nu_{H A}^{r e}$} & \multirow{2}{*}{ Variation } \\
\hline & $m \times 10^{-5}$ & $b \times 10^{-5}$ & & & & & & & \\
\hline & $(\mathrm{mm} / \mathrm{mm}) / \mathrm{MPa}$ & $\mathrm{mm} / \mathrm{mm}$ & $\mathrm{mm}$ & $\mathrm{MPa}$ & $\mathrm{MPa}$ & $\%$ & & & $\%$ \\
\hline PI_1750_1-1(4H) & 1.70 & -1.07 & 1.31 & 141088 & 139289 & 1.275 & 0.349 & 0.411 & 15.008 \\
\hline PI_1750_2-1(1H) & 1.95 & -24.0 & 1.50 & 123380 & 121838 & 1.250 & - & - & - \\
\hline PI_1750_2-1(2H) & 1.72 & -30.8 & 1.32 & 139896 & 138176 & 1.229 & - & - & - \\
\hline PI_1750_2-1(3H) & 1.59 & -20.5 & 1.23 & 150813 & 148847 & 1.303 & - & - & - \\
\hline PI_1750_2-2(1H) & 2.06 & -29.0 & 1.59 & 116585 & 115090 & 1.282 & 0.171 & 0.201 & 14.968 \\
\hline PI_1750_2-2(2H) & 1.75 & -3.22 & 0.05 & 137105 & 135366 & 1.268 & 0.204 & 0.241 & 15.010 \\
\hline PI_1750_3-1(3H) & 1.84 & -1.64 & 1.41 & 130846 & 129251 & 1.219 & 0.327 & 0.384 & 14.990 \\
\hline PI_1750_3-2(1H) & 2.13 & -1.16 & 1.64 & 112713 & 111293 & 1.260 & 0.287 & 0.337 & 15.011 \\
\hline PI_1750_3-2(2H) & 1.93 & -1.78 & 1.48 & 124267 & 123043 & 0.985 & 0.337 & 0.372 & 09.387 \\
\hline PI_1750 & - & - & - & 130743 & 129133 & 1.231 & 0.279 & 0.324 & 13.907 \\
\hline
\end{tabular}
surface while column 8 sets it down at the outermost surface; the last column corresponds to their variation. It can be seen that the variations shown in column 6 are close to zero and values of $E_{H}^{o}$ rest approximate to the computed values using the standard method.

Table 4

Elastic constants calculated at the reference plane of the thinner test probes (PI_1750), Ref. 7 
E. Vargas-Rojas, C. Palacios-Montúfar, H. Hernández-Moreno, and J.L. González-Velázquez

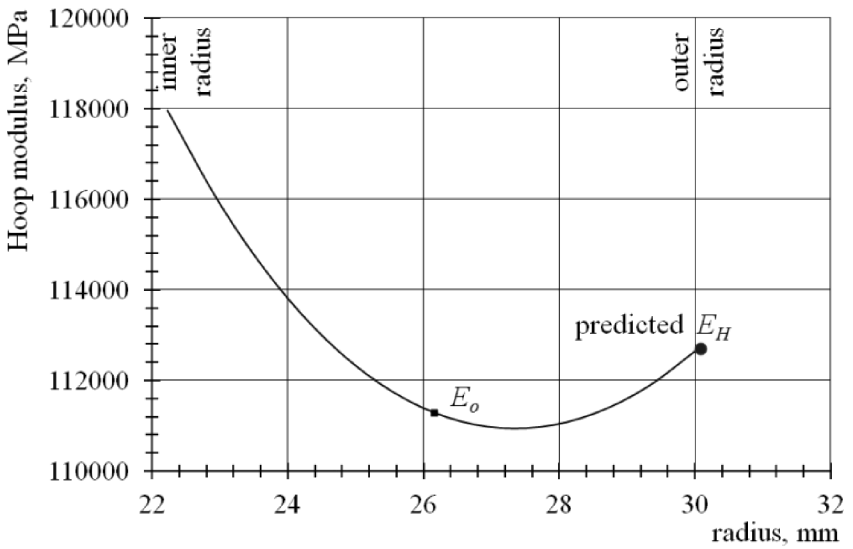

Fig. 8. Through-the-thickness variation of the hoop modulus of the reinforced material. Testing conditions: PI_1750_3-2(1C); $p=$ $25 \mathrm{MPa} ; r=26.15 \mathrm{~mm} ; r_{e}=30.08 \mathrm{~mm} ; \varepsilon_{H}^{r e}=0.000521 \mathrm{~mm} / \mathrm{mm}$
3.5. Extended method. Once the elastic constants are calculated at the middle-surface, the average values listed in Table 4 are used as input data of the extended method, whose flowchart is depicted in Fig. 9. This method differs from the standard method from step 1 through step 5. Steps 1 and 2 consider as input data the engineering constants of the metallic liner, and of the RML at its middle-surface: $E_{H}^{o}, \nu_{H A}^{o}$, $E_{A}^{o}, \nu_{A H}^{o}$, (cf. Appendix B - Fig. B1). The G-Ep reinforcement layer is considered as a single layer, i.e, $\left[0^{\circ}\right]_{1}$, and it is assumed that $E_{A}^{o}=E_{A}$ and $\nu_{H A}^{o}=\nu_{H A}$. Next, in step 3, the stiffness matrix of the metallic liner is calculated with expression (3a) that is the same as expressions (A2f) through (A2h). Similarly, in step 4 the compliance matrix of the RML is calculated with expression (3b) or (A2a) through (A2e). The stiffness matrix of the G-Ep reinforcement is computed with expression (3c). Finally, the extensional stiffness matrix

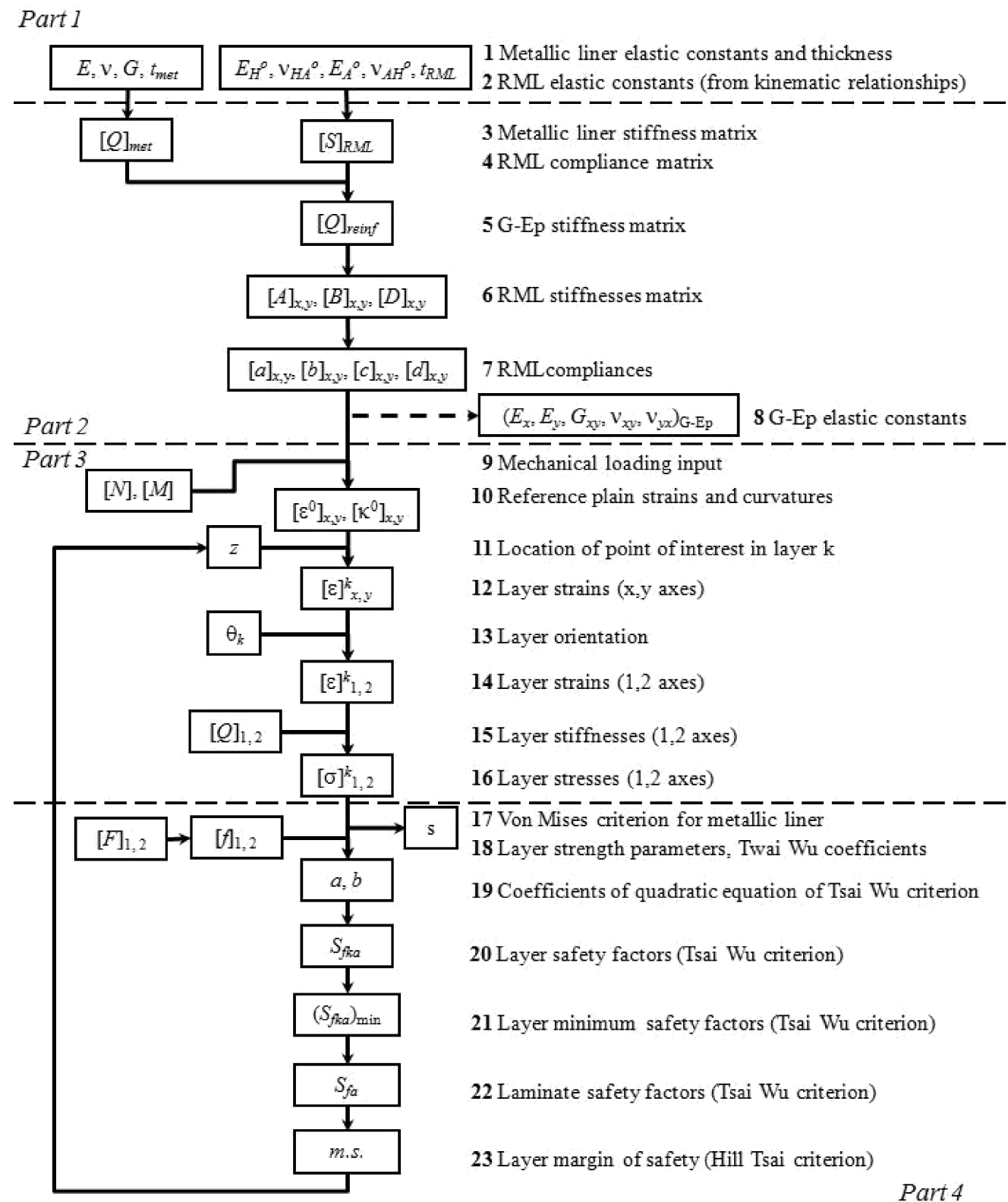

Fig. 9. Flow chart for stress and failure analysis of multidirectional laminates using the extended method 
Approximate mechanical behavior analysis of a thick-wall metallic liner reinforced...

of the RML is found with expression (3d). From step 9 onwards, the procedure explained in Subsec. 3.1 remains the same.

$$
\left[Q_{i j}\right]_{\text {met }}=\left[\begin{array}{ccc}
E / 1-\nu^{2} & \nu E /\left(1-\nu^{2}\right) & 0 \\
\nu E /\left(1-\nu^{2}\right) & E /\left(1-\nu^{2}\right) & 0 \\
0 & 0 & E /(2(1+\nu))
\end{array}\right] \text {, }
$$$$
\left[S_{i j}\right]_{R M L}=\left[\begin{array}{ccc}
1 / E_{H}^{o} & -\nu_{A H}^{o} / E_{A}^{o} & 0 \\
-\nu_{H A}^{o} / E_{H}^{o} & 1 / E_{A}^{o} & 0 \\
0 & 0 & 1 / G_{H A}
\end{array}\right] \text {, }
$$$$
\left[Q_{i j}\right]_{G-E p}=\left\{\left[A_{i j}\right]-\left[Q_{i j}\right]_{m e t} t_{m e t}\right\}^{/} t_{G-E p},
$$$$
\left[A_{i j}\right]=\left[S_{i j}\right]_{R M L}^{-1} t .
$$

In order to be able to corroborate the results obtained with both methods, matrix $A_{i j}$ is recalculated, as well as the engineering constants of the RML. Thus, Fig. 10 is the plot of the hoop strain as a function of pressure of the outermost layer using the expanded method, and Fig. 11 is the plot of the safety factor for each layer as a function of internal pressure of the RML and of the nRML (not shown due to practical purposes, however it remains the same as in Fig. 5) using the improved method. As it can be seen, a considerably increase of the failure point is achieved for the thinner test probe, going from $320 \mathrm{MPa}$ (cf. Fig. 5) to $650 \mathrm{MPa}$ (6500 bar or $94.3 \mathrm{ksi}$ ).

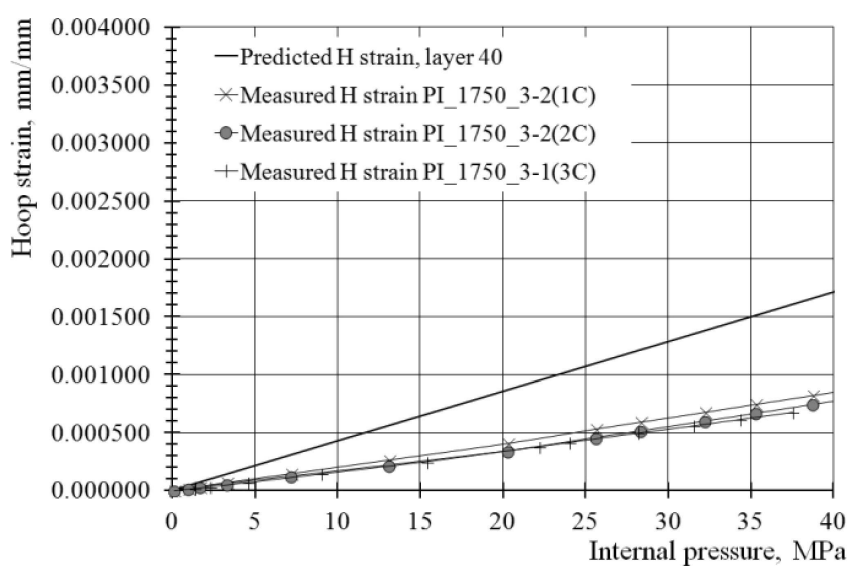

Fig. 10. Predicted and measured hoop strains at the outermost layer of thinner test probe PI_1750_3 assessed with the expanded method

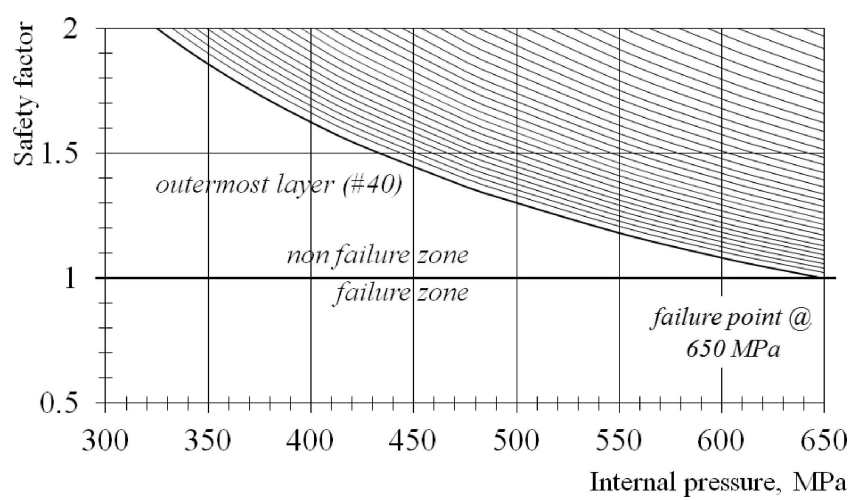

Fig. 11. Safety factor as a function of internal pressure of the RML valuated with the expanded method. RML: $\emptyset_{e} 60.16 \mathrm{~mm} \times$ $\emptyset_{i} 44.45 \mathrm{~mm}$
3.6. Specific mechanical properties. As stated in the Introduction, high pressures can be borne by increasing the thickness of the metallic tubing, so as well weight and cost. Searching to accomplish design criteria intended for transport applications, the specific mechanical properties should be increased as much as they can, like specific strength or specific stiffness, i.e., maximum bearable stress $\sigma_{\max }$ divided by the density; or the elastic modulus $E$ divided by the density. Following these definitions, the specific stiffness of the steel is therefore $25.3 \times 10^{6}(\mathrm{~m} / \mathrm{s})^{2}$. In line with the results listed in Tables 1 and $2\left(E_{H}\right.$ divided by density of RML) an average value of $28.5 \times 10^{6}(\mathrm{~m} / \mathrm{s})^{2}$ is achieved for both thinner and thicker RML test probes in the hoop direction. However, lower specific stiffness values are achieved in the axial direction where the reinforcement has no great effects: $16.4 \times 10^{6}(\mathrm{~m} / \mathrm{s})^{2}$, and $21.3 \times 10^{6}(\mathrm{~m} / \mathrm{s})^{2} \quad\left(C_{-} 1750 \_1\right.$ test probe, and the average of thicker test probes, respectively).

3.7. Costs. Gay in [6] establishes that the cost of a kilogram of composite is calculated considering material, transformation, mortgage of equipment and finishing. Thus, concerning this application, the material costs of the reinforcement constituents available in the local market are listed in rows 1 and 2 of Table 5; value in row 3 corresponds to their sum. Price of steel tubing (raw) is listed in row 4, and its transformation cost is computed in row 5. Row 6 is the cost of the metallic liner following Gay's definition of costs. Finally, row 7 is the cost of RML obtained with the sum of values in rows 3, and 6 . In Table 5 an exchange rate of $\$ 11$ pesos (local currency) to $\$ 1$ USD is considered. Local taxes are already comprised as well.

Comparison of costs between the nRML and the RML based on performance could be achieved by estimating the value of the metallic liner that would stand the same pressure as computed with the standard and the expanded methods (320 MPa and $650 \mathrm{MPa}$, respectively); however, the predicted pressures are extremely high, and when estimating the outer diameter with the Von Mises criterion there is no sufficient metallic wall thickness capable of withstanding them. Therefore, an accepted design criteria that allows to compare the nRML v. RML are the specific stiffness divided by cost (4a), and the specific strength divided by cost (4b) [6], reported in Table 6 under columns 2 and 5. Column 4 corresponds to an equivalent $\sigma_{y}$ that would be necessary to resist the internal pressure listed in column 3; an uniaxial state of stress is considered. The equivalent $\sigma_{y}$ is calculated with expression (1b)

$$
\begin{gathered}
(E / \rho) / \text { cost, } \\
\left(\sigma_{\max } / \rho\right) / \text { cost. }
\end{gathered}
$$

In order to estimate costs of the RML in comparison with the metallic barrel, a reference to compare with needs to be established. Gay in [6] considers a unitary global cost for the non-composite solution. Thus, for this analysis the cost of the metallic barrel per test probe is normalized to 1 in column 6. As the RML is fabricated from the same metallic barrel, a supplementary cost due to the G-Ep technology is expected. 
Table 5

Costs of constituent materials

\begin{tabular}{cccc}
\hline \hline No. & Concept & Cost $\$ / \mathrm{kg}$ & Commentaries \\
\hline 1. & Fiber roving & 0.76 & Price of a fiber-roving spool of $13 \mathrm{~kg}$ in local market, $\$ 95$ pesos. \\
\hline 2. & Epoxy resin & 12.54 & 138 pesos $/ \mathrm{kg}$. \\
\hline 3. & G-Ep reinforcement & 13.30 & Costs of fiber plus resin. \\
\hline 4. & Steel tube (raw) & 3.10 & Price in local market of unprocessed material. \\
\hline 5. & Steel tube (transformed) & 23.20 & Price of transformation of the metallic liner. \\
\hline 6. & Steel tube, total & 26.30 & Sum of raw material plus transformation. \\
\hline 7. & RML & 39.60 & G-Ep reinforcement and steel tube (material and transformation). \\
\hline
\end{tabular}

Table 6

Costs comparison

\begin{tabular}{|c|c|c|c|c|c|c|c|}
\hline 1. & & & 3. & 4. & 5. & 6. & \\
\hline Material & $\begin{array}{r}(E / \rho \\
(\mathrm{m}\end{array}$ & $\begin{array}{l}\text { ost } \times 10^{6}, \\
/(\$ / \mathrm{kg})\end{array}$ & $p, \mathrm{MPa}$ & $\sigma_{y}, \mathrm{MPa}$ & $\left(\sigma_{\max } / \rho\right) / \operatorname{cost},(\mathrm{m} / \mathrm{s})^{2} /(\$ / \mathrm{kg})$ & Normalized cost & Commentaries \\
\hline \multirow[t]{2}{*}{ nRML } & \multicolumn{2}{|c|}{$0.96^{*}$} & 61 & 520 & $2510^{*}$ & 1 & *Cost corresponds to row 6 of Table 5 . \\
\hline & $E_{H}$ & $E_{A}$ & - & - & - & - & - \\
\hline \multirow{2}{*}{ RML (thinner) } & \multirow{2}{*}{$0.72 * *$} & \multirow{2}{*}{$0.41 * *$} & 320 & 1090 & $5856^{* *}$ & \multirow{2}{*}{1.08} & \multirow{2}{*}{$* *$ Cost corresponds to row 7 of Table 5} \\
\hline & & & 650 & 2210 & $11874 * *$ & & \\
\hline
\end{tabular}

The cost of the G-Ep reinforcement per test probe is set in terms of the mass fractions of each constituent plus their unitary costs per unit of mass by means of expression (5a), where $M_{f}$ stands for the fiber mass fraction and $M_{m}$ is the matrix mass fraction. Mass fraction of a constituent can be expressed as the product of its volume fraction, total volume, and constituent's density. Concerning the RML, the volume is expressed as the annular section of the G-Ep reinforcement times the length of the test probe, therefore expression (5a) can be expressed in terms of these parameters in the form of expression (5b). With the aid of the costs of the constituents of the RML listed in Table 5 is possible to compute a value of \$1.14 USD/probe of the G-Ep reinforcement considering materials, versus $\$ 13.60 \mathrm{USD} /$ probe of the nRML considering material ( $\$ 1.60 \mathrm{USD} /$ probe), and transformation $(\$ 12.00$ $\mathrm{USD} /$ probe). With these data it is possible to compute the relative increment in cost due to the G-Ep reinforcement of $8.4 \%$ with respect to the cost of the nRML.

$$
\begin{gathered}
\operatorname{cost}_{\mathrm{G}-\mathrm{Ep}}=M_{f} \operatorname{cost}_{f}+M_{m} \operatorname{cost}_{m}, \\
\operatorname{cost}_{\mathrm{G}-\mathrm{Ep}}=v_{T}\left(V_{f} \rho_{f} \operatorname{cost}_{f}+V_{m} \rho_{m} \operatorname{cost}_{m}\right) .
\end{gathered}
$$

\section{Analysis of results}

When analytical results of the engineering constants are compared with experimental data reported in Table 1, the hoop elastic moduli of the thinner test probes show an average variation of near $29.4 \%$ while the thicker test probes present a lower variation of near $19 \%$. However, on the subject of the major Poisson ratio, the thinner test probes have an even lower and more acceptable variation of $7.5 \%$ while the thicker ones reach $14 \%$. That is, the hoop elastic modulus shows a bigger dispersion on its results than the Poisson ratio. These variations need to be reduced as much as possible if transport applications are envisaged as potential.

It is to be noticed that the traditionally accepted equality between the elements $Q_{12}$ and $Q_{21}$ of the thinner RML obtained from experimental data is not accomplished as expected, as shown in Table 7, where the elements listed in column A should be the same to those listed in column $\mathrm{C}$ for each type of test probe; the same situation should be for elements under columns B and D. These relationships are established from figures in bold font issued from Table 1. When such equality exists it can be corroborated from expressions (A2c) and (A2d) that $\nu_{H A} / E_{H}=\nu_{A H} / E_{A}$. In order to take into account these inequalities, the mathematical expressions used in the numerical tool are reviewed and posed (cf. Eqs. (A2c), (A2d), (A3d) and (A3e)). Actually the thicker test probes positively accomplish this equality, while the thinner ones fail when quotients obtained with experimental data are compared. Hence, thicker test probes present more reliable results of their axial engineering constants than the thinner ones.

The elastic constants in the hoop direction are numerically determined for the G-Ep reinforcement system and compared with experimental data using the CLT in view of plain laminates. The introduction of the second-order theory, and therefore curvature effects, reduces the variation between experimental and numerically predicted values. However, when considering the mechanical properties of the whole G-Ep reinforcement as a single layer, instead of the mechanical properties of 40 unidirectional laminae, and by avoiding the use of the expressions of micromechanics ((A1a) through (A1e)), a reduction of the variation between experimental measurements and numerical results is achieved. 
Approximate mechanical behavior analysis of a thick-wall metallic liner reinforced...

Table 7

Quotients of the Poisson to elastic modulus ratios for each type of test probe

\begin{tabular}{ccccc}
\hline \hline \multirow{2}{*}{ Type of test probe } & \multicolumn{2}{c}{$\nu_{H A} / E_{H} \times 10^{-6} 1 / \mathrm{MPa}$} & \multicolumn{2}{c}{$\nu_{A H} / E_{A} \times 10^{-6} 1 / \mathrm{MPa}$} \\
\cline { 2 - 5 } & A. & B. & C. & D. \\
\cline { 2 - 4 } PI_1750 & $\frac{0.324}{130743}=2.48$ & $\frac{0.300}{92374}=3.25$ & $\frac{0.289}{76888}=3.76$ & $\frac{0.243}{74925}=3.24$ \\
\hline PI_1625 & $\frac{0.348}{136288}=2.55$ & $\frac{0.300}{110468}=2.72$ & $\frac{0.251}{99444}=2.52$ & $\frac{0.261}{96035}=2.72$ \\
\hline
\end{tabular}

The reasons to consider the RML as a bi-layered material are delineated next. The analysis of a laminated structure like the G-Ep reinforcement is different with respect to a metallic layer. On the one hand, CLT assumes that a layered structure is a succession of a finite number of orthotropic surfaces separated by ultra thin isotropic layers (that correspond to the embedding matrix) acting as an integral structural element whose mechanical behavior is the sum of its constituents under numerous assumptions, like for example, the resistance considered along the thickness of a laminate could be set as the in-plane transverse tensile strength of an unidirectional lamina as referred by Schubel [16]. Being more conservative, this resistance could be set as that of the resin. On the other hand, a metallic interface is seen as a unique and continuous layer, disregarding its molecular structure of matter and picturing it without gaps or empty spaces, therefore following the hypothesis of a continuum [17]. Moreover, certain strength predictions for composites can be based on micromechanical analysis and point failure criteria. However, even when predictions are accurate with regard to failure initiation at critical points, they are only approximate as far as global failure of the lamina is concerned. The interaction of different failure mechanisms makes it even more difficult to obtain reliable strength predictions. For the aforementioned reasons, a macromechanical approach to failure analysis may be preferable [3]. In effect, there are many mathematical models issued from the micromechanics viewpoint that allow to estimate the elastic behavior of composite materials that are sensitive to their constituents. For example, the expression that defines the longitudinal modulus, Eq. (A1a), shows better results when considering high fiber volume fractions. However, in respect of transversal modulus there are significant variations because of the transversal isotropic nature of each single ply. This consideration allows to consider the lamina as a fragile elastic material along the fibers, in accordance to Eq. (A1); and as a previously damaged visco-elastic (or visco-plastic) material in the transverse direction of the fibers. In such a case, the total deformation of the material in the transverse direction may be the sum of an inelastic plus a plastic deformation, as suggested by Gasquez in [18]. Thereof, caution on the use of micromechanics formulations should be taken if the whole range of the mechanical behavior of the material rests unknown and if no damage is assumed a priori. For design considerations in mind, an approach that considers previous damage along the transverse direction of the fibers of a unidirectional ply should be considered so as to incorporate micromechanical relationships and the mechanical properties of the constituents (fiber and resin).

Even though the increase of the specific stiffness is quantitatively small, it is shown that by considering this kind of reinforcement, an effective augment of the specific stiffness is achieved mostly in the longitudinal direction of the fibers, while along the transverse direction the specific stiffness rests lower than that of the steel, highlighting its orthotropic nature. Additional considerations should be taken in order to achieve a bigger specific stiffness and performance by means of carbon fiber rovings overwrapped at the outermost layers, and higher fiber volume fractions over $60 \%$. Moreover, concerning applications fabricated with the filament-winding process, other winding directions should be considered, achieving by this the improvement of the specific mechanical properties in various directions.

Looking forward to further related studies, and in an attempt to reduce even more the gap between the experimental and the predicted behavior depicted in Fig. 10, several tasks are recommended such as: (1) to reduce the residual strains during the filament-winding process by considering a multistage cure, or an in situ cure, or a continuous curing process in order to reduce the residual stress state over the conventional one-stage cure. (2) The actual strength of the system needs to be experimentally determined, in particular the strength parameters of the G-Ep reinforcement, so they can be input in the improved method, instead of calculating them with Eq. (3c). (3) Regarding curvature effects, the stiffness matrix of the reinforced tubing becomes more complex when the effects of the curvature are considered, as shown by Hernández in [19, 20]. So, if a model with more complete assumptions that take into account curvature effects is desired, then the kinematics relationships for shells of revolution presented by Flügge in [21] should be taken into account. (4) Some of the hypotheses of the CLT are commented in Subsec. 3.1, such as the neglect of normal stresses and the need of perfectly bonded layers of the laminate. Regarding the RML, a radial component of stress exists, and continuity is not necessarily assured at the interface between the metallic layer and the G-Ep reinforcement. Extreme attention should be paid during fabrication. Further studies are recommended to be conducted to ensure this assumption. (5) To conduct a second-order theory analysis of the elastic constants in the axial direction. (6) Supplementary considerations comprise the possibility of plastic behavior of the metallic layer once its yielding stress is exceeded, while the composite reinforcement has not failed. 
Finally, an extensive cost analysis is executed and resumed in Table 6. Columns 2 and 5 present relative results that may need to be compared with actual data of other applications developed with composites technology. It is desirable that specific mechanical properties are as high as possible. However, in column 2, the RML presents figures of specific stiffness lower than those of the nRML. This situation is as expected for this particular application because both the RML and nRML share the same metallic liner, hence the RML is by force of circumstance more expensive and heavy than the nRML. Cost comparison then needs to be observed under the viewpoint of performance. Under this regard, in Fig. 4 it can be seen that the variation between the measured hoop strain increases with respect to the predicted hoop strain, as pressure increases. Enquiring about how to minimize this variation by considering more accurate input data, Fig. 10 is obtained when taking into account the average elastic constants listed in Table 4, i.e., the elastic constants calculated in the middle-surface of the RML. In this way, a better correlation of numerical with experimental data is obtained, allowing to increase the value of the safety factors, as well as the sustained internal pressure from $55 \mathrm{MPa}$ for the nRML, to 320 for the RML using the CLT, to $650 \mathrm{MPa}$ for the same RML with the improved method here proposed, i.e., almost 12 times the internal pressure bearable by the nRML. Moreover, in column 5, specific strength is calculated and related to cost. In this case, values augment as desired, being higher for the RML than for the nRML. Closing down, the composite reinforcement represents an additional $8.4 \%$ of the global cost of the metallic liner. It rests to experimentally validate the strength performance of the RML.

\section{Conclusions}

A G-Ep reinforcement system for tubular members under internal pressure based on a polymeric matrix composite is fabricated and mechanically characterized by means of an internal pressure and a compression test.

A numerical method based on the CLT that takes into account curvature effects is programmed and allows to predict the mechanical behavior and the failure point. From the obtained results it can be stated that the G-Ep composite system is effective because it increases the specific stiffness in the hoop direction, i.e., in the direction of the principal stress with greater magnitude, and the specific strength. Moreover, for the particular case analyzed in this document, a polymericcomposite reinforcement of this kind can increase from 2 up to almost 12 times the maximum internal pressure that a nRML can bear before failure of the reinforcement, by almost trebling the original thickness, doubling the weight of the metallic liner, but without considerably increasing cost $(8.4 \%)$. Under this regard, a RML seems an effective solution for high and very-high hydraulic pressure systems.

In line with the results of this study and searching to reduce incertitude on the prediction of the global mechanical behavior of the RML, the mechanical properties of a single ply or of the whole laminate as a continuum are recommend- ed to be used as input data, instead of using micromechanical relationships.

\section{Appendix A. Classical Lamination Theory, CLT}

This section is devoted to show the equations that describe the linear elastic response of a composite layered structure subjected to in-plane loads and bending moments (no curvature effects included). The procedure is in accordance with the flow chart illustrated in Fig. 3.

Step 1. Calculate basic lamina properties $\left(E_{1}, E_{2}, \nu_{12}\right.$, $G_{12}$ ), as a function of constituent materials properties, according to the local reference axes illustrated in Fig. 1, using Eqs. (A1).

$$
\begin{gathered}
E_{1}=E_{m} V_{m}+E_{f} V_{f}, \\
1 / E_{2}=V_{m} / E_{m}+V_{f} / E_{f}, \\
\nu_{12}=\nu_{m} V_{m}+\nu_{f} V_{f}, \\
\nu_{21}=E_{2} \nu_{12} / E_{1}, \\
G_{12}=G_{m} /\left(\left(1-V_{f}\right)+G_{m} V_{f} / G_{f}\right) .
\end{gathered}
$$

Step 2. Compute each ply stiffness $[Q]_{1,2}$ with Eqs. (A2).

$$
\begin{gathered}
Q_{11}=E_{1} /\left(1-\nu_{12} \nu_{21}\right), \\
Q_{22}=E_{2} /\left(1-\nu_{12} \nu_{21}\right), \\
Q_{12}=-\nu_{12} E_{2} /\left(1-\nu_{12} \nu_{21}\right), \\
Q_{21}=-\nu_{21} E_{1} /\left(1-\nu_{12} \nu_{21}\right), \\
Q_{66}=G_{12} .
\end{gathered}
$$

The elements of the stiffness matrix of isotropic materials are referenced from Jones, [15]:

$$
\begin{gathered}
Q_{11}=Q_{22}=E /\left(1-\nu^{2}\right), \\
Q_{12}=Q_{21}=\nu E /\left(1-\nu^{2}\right), \\
Q_{66}=Q_{21}=E /(2(1+\nu))=G .
\end{gathered}
$$

Step 3. Enter the number of layers, $n$, and orientation of principal material axis, $\theta_{k}$, of layer $k$.

Step 4. Calculate the transformed layer stiffness $[Q]_{x, y}^{k}$ with Eqs. (A3) of layer $k$ referred to the laminate coordinate system, i.e., the global reference system $x, y$ or $H, A$, respectively; in consequence, $\theta=0^{\circ}$ and the filament winding angle, $\alpha=90^{\circ}$. Note: The angle of the local reference system with respect to the global reference system, $\theta$, is not necessarily complementary to the filament-winding angle $\alpha$. For this particular case study the main independent variable is $\theta$ rather than $\alpha$. Additionally, it is considered that $\bar{Q}_{12}(\theta) \neq \bar{Q}_{21}(\theta)$.

$$
\{\sigma\}_{x y}=\left[\bar{Q}_{i j}(\theta)\right]_{x y}\{\varepsilon\}_{x y},
$$

where

$$
\begin{gathered}
\bar{Q}_{11}(0)=\bar{E}_{1}, \\
\bar{Q}_{22}(0)=\bar{E}_{2}, \\
\bar{Q}_{33}(0)=G_{12}, \\
\bar{Q}_{12}(0)=\nu_{21} \bar{E}_{1}, \\
\bar{Q}_{21}(0)=\nu_{12} \bar{E}_{2}, \\
\bar{Q}_{13}(0)=\bar{Q}_{23}(0)=2 G_{12},
\end{gathered}
$$


Approximate mechanical behavior analysis of a thick-wall metallic liner reinforced...

$\bar{E}_{1}=E_{1} /\left(1-\nu_{12} \nu_{21}\right), \quad \bar{E}_{2}=E_{2} /\left(1-\nu_{12} \nu_{21}\right)$.

Step 5. Enter the through-the-thickness coordinates $z_{k}$ and $z_{k-1}$ of the surfaces of layer $k$ according to Fig. A1.

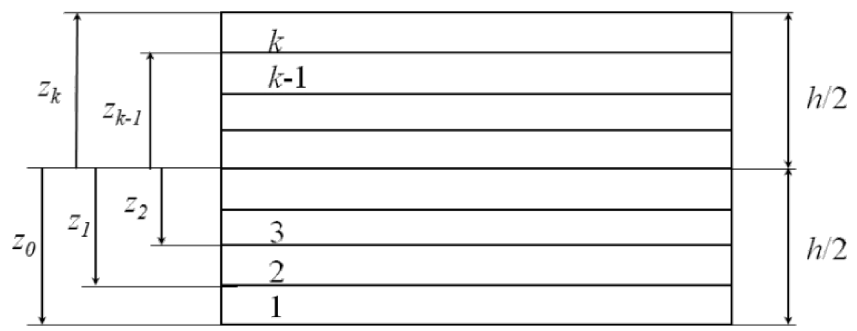

Fig. A1. Laminate construction and ply designations

Step 6. Calculate laminate stiffness matrices $[A],[B]$, and $[D]$ using Eqs. (A4).

$$
\begin{gathered}
A_{i j}=\sum_{k=1}^{k=n} \bar{Q}_{i j}^{k}(\theta)\left(z_{k}-z_{k-1}\right), \\
B_{i j}=\sum_{k=1}^{k=n} \bar{Q}_{i j}^{k}(\theta)\left(z_{k}^{2}-z_{k-1}^{2}\right) / 2, \\
D_{i j}=\sum_{k=1}^{k=n} \bar{Q}_{i j}^{k}(\theta)\left(z_{k}^{3}-z_{k-1}^{3}\right) / 3 .
\end{gathered}
$$

Step 7. Calculate laminate compliance matrices $[a],[b],[c]$, and $[d]$ using Eqs. (A5).

$$
\begin{gathered}
{[a]=\left[A^{-1}\right]-\left\{\left[B^{*}\right]\left[D^{*-1}\right]\right\}\left[C^{*}\right],} \\
{[b]=\left[B^{*}\right]\left[D^{*-1}\right],} \\
{[c]=-\left[D^{*-1}\right]\left[C^{*}\right],} \\
{[d]=\left[D^{*-1}\right],} \\
{\left[B^{*}\right]=-\left[A^{-1}\right][B],} \\
{\left[C^{*}\right]=[B]\left[A^{-1}\right],} \\
{\left[D^{*}\right]=[D]-\left\{[B]\left[A^{-1}\right]\right\}[B] .}
\end{gathered}
$$

Step 8. Calculate the engineering elastic constants of the RML.

Step 9. Enter mechanical loading, i.e., forces $[N]_{x, y}$ and moments $[M]_{x, y}$. The loading condition for an internal hydrostatic pressure test with no end effects is represented by the next expressions, in the form of a column vector, Eq. (A6): $N_{A}=0, N_{H}=p r_{i}$, $N_{A H}=0, M_{A}=0, M_{H}=0, M_{A H}=0$.

Step 10. Calculate reference plane strains, $\left[\varepsilon^{o}\right]_{x, y},\left[\kappa^{o}\right]_{x, y}$, using Eq. (A7) for plain laminates:

$$
\left\{\begin{array}{l}
\varepsilon_{x y}^{o} \\
\kappa_{x y}^{o}
\end{array}\right\}=\left[\begin{array}{ll}
a_{i j} & b_{i j} \\
b_{i j} & d_{i j}
\end{array}\right]\left\{\begin{array}{l}
N_{x y} \\
M_{x y}
\end{array}\right\} .
$$

Step 11. Enter through-the-thickness coordinate $z$, of point of interest in layer $k$.

Step 12. Calculate the layer strains $[\varepsilon]_{x, y}^{k}$, referred to laminate reference axes $(x, y)$, using Eq. (A8):

$$
\{\varepsilon\}_{x y}=\left\{\varepsilon^{o}\right\}_{x y}+z\{\kappa\}_{x y} .
$$

Steps 13 and 14. Layer orientation is required to calculate local layer strains $[\varepsilon]_{1,2}^{k}$, referred to local reference axes $(1,2)$.

$$
\begin{gathered}
\{\varepsilon\}_{1,2}=[T(0)]\{\varepsilon\}_{x, y}=\left\{\begin{array}{c}
\varepsilon_{1} \\
\varepsilon_{2} \\
\gamma_{12}
\end{array}\right\} \\
=\left[\begin{array}{lll}
1 & 0 & 0 \\
0 & 1 & 0 \\
0 & 0 & 1
\end{array}\right]\left\{\begin{array}{c}
\varepsilon_{x} \\
\varepsilon_{y} \\
\gamma_{x y}
\end{array}\right\} .
\end{gathered}
$$

Steps 15 and 16. Layer stiffness matrix (step 2) is required to calculate layer stresses $[\sigma]_{1,2}^{k}$, referred to the layer principal axes $(1,2)$, using Eq. (A10):

$$
\{\sigma\}_{1,2}=[Q]_{1,2}\{\varepsilon\}_{1,2} .
$$

Step 17. Taking into account that the metallic liner is the ply number one and that its stress state is known, the safety factor for the metallic liner can be determined using the Von Mises yield criterion using Eq. (A11):

$$
\sqrt{\left(\sigma_{1}-\sigma_{2}\right)^{2}+\left(\sigma_{2}-\sigma_{3}\right)^{2}+\left(\sigma_{3}-\sigma_{1}\right)^{2}}<\sqrt{2} \sigma_{y} / s .
$$

Step 18. Enter lamina strengths $[F]_{1,2}$ and calculate Tsai-Wu coefficients $[f]_{i},[f]_{i j}$ using Eqs. (A12). The Tsai-Wu criterion is operationally simple; therefore it is preferred for computation. The goal in this case is to determine the safety factor for a given loading

$$
\begin{gathered}
f_{1}=1 / F_{1 t}-1 / F_{1 c}, \\
f_{11}=1 / F_{1 t} F_{1 c}, \\
f_{2}=1 / F_{2 t}-1 / F_{2 c}, \\
f_{22}=1 / F_{2 t} F_{2 c}, \\
f_{66}=1 / F_{6}^{2}, \\
f_{12} \approx-\left(\left(f_{11} f_{22}\right)^{1 / 2}\right) / 2 .
\end{gathered}
$$

Steps 19 and 20. Calculate layer safety factors, $S_{f k a}$, by means of Eqs. (A13). $S_{f k a}$ is the safety factor of layer $k$ for the actual state of stress.

$$
\begin{gathered}
a=f_{11} \sigma_{1 k}^{2}+f_{22} \sigma_{2 k}^{2}+f_{66} S_{f k} \tau_{6 k}^{2}+2 f_{12} S_{f k} \sigma_{1 k} \sigma_{2 k}, \\
b=f_{1} S_{f k} \sigma_{1 k}+f_{2} S_{f k} \sigma_{2 k}, \\
S_{f k}=\left(-b \pm \sqrt{b^{2}+4 a}\right) /(2 a), \\
S_{f k a}=\left(-b+\sqrt{b^{2}+4 a}\right) /(2 a) .
\end{gathered}
$$

Steps 21 and 22. Determine the laminate safety factor $S_{f a}$ with Eq. (A14). The procedure of step 18 is carried out repeatedly for all layers of the laminate to find the minimum values of $S_{f k a}$. These minimum values are the safety factors of the laminate based on the FPFA. Thus,

$$
S_{f a}=\left(S_{f k a}\right)_{\min }
$$

Step 23. Calculate layer margins of safety by means of Eq. (A15) according to Hill-Tsai failure criterion (for a tensional state of stress):

$$
\sigma_{1}^{2} / F_{1 t}^{2}+\sigma_{2}^{2} / F_{2 t}^{2}-\sigma_{1} \sigma_{2} / F_{1 t}^{2}+\tau_{6}^{2} / F_{6}^{2}=1 .
$$




\section{E. Vargas-Rojas, C. Palacios-Montúfar, H. Hernández-Moreno, and J.L. González-Velázquez}

\section{Appendix B. Engineering constants of G-Ep reinforcement and RML}

In Appendix B, the procedure explained in Appendix A is executed for the material under study. Firstly, the properties of a basic lamina are calculated in order to determine the mechanical properties of the G-Ep reinforcement as a single layer and of the RML constructed with two layers (cf. Fig. B1). The engineering constants of a basic unidirectional ply, using Eqs. (A1) and taking into account the experimental data of Table 2, are presented next: $E_{1}=33583 \mathrm{MPa}$, $E_{2}=4856 \mathrm{MPa}, G_{12}=1871 \mathrm{MPa}, \nu_{12}=0.3, \nu_{12}=0.043$ With these results, the stiffness matrix of an unidirectional ply is computed with the aid of Eqs. (A2):

$$
[Q]_{1,2}=\left[\begin{array}{ccc}
34026 & 1476 & 0 \\
1477 & 4920 & 0 \\
0 & 0 & 1871
\end{array}\right] \mathrm{MPa} .
$$

Then, the mechanical properties of the G-Ep reinforcement are calculated. Since the orientation of each ply is $0^{\circ}$, the transformed layer stiffness (step 4) is the same as the stiffness matrix of each layer (step 3). The extensional stiffness matrix of the G-Ep reinforcement can be calculated using Eq. (5a):

$$
\left[A_{i j}\right]_{G-E p}=\left[\begin{array}{ccc}
172852 & 7500 & 0 \\
7500 & 24995 & 0 \\
0 & 0 & 9505
\end{array}\right] \mathrm{N} / \mathrm{mm} .
$$

The engineering constants of the G-Ep reinforcement listed in Table B1 are obtained after inverting the matrix $A_{i j}$, equating each element $a_{i j}$ with the corresponding elements of the compliance matrix, Eq. (3b), and solving for the respective engineering constant. Reference axes are in accordance with Fig. 1.

Table B1

Mechanical properties of the metallic and the G-Ep reinforcement plies of the RML

\begin{tabular}{ll}
\hline \hline Ply 1, metallic & Ply 2, G-Ep reinforcement \\
\hline$E=200 \mathrm{GPa}$ & $E_{1}=33583 \mathrm{MPa}$ \\
$G=79 \mathrm{GPa}$ & $E_{2}=4856 \mathrm{MPa}$ \\
$\nu=0.30$ & $\mathrm{G}_{12}=1871 \mathrm{MPa}$ \\
$t_{\text {met }}=2.78 \mathrm{~mm}$ & $\nu_{12}=0.30, \nu_{21}=0.0434$ \\
$\sigma_{y}=520 \mathrm{MPa}$ & $t_{\text {reinf }}=5.08 \mathrm{~mm}$ \\
\hline
\end{tabular}

The same procedure is accomplished for the RML, which does not have the symmetry and regularity of the G-Ep reinforcement alone; its input properties are listed in Table B1. The elements of the stiffness matrix of the isotropic metallic liner are computed with expressions (A2f) through (A2g).

$$
\begin{gathered}
{[Q]_{G-E p}=\left[\begin{array}{ccc}
34026 & 1476 & 0 \\
1477 & 4920 & 0 \\
0 & 0 & 1871
\end{array}\right] \mathrm{MPa},} \\
{[Q]_{\text {tubing }}=\left[\begin{array}{ccc}
219780 & 65930 & 0 \\
65930 & 219780 & 0 \\
0 & 0 & 79000
\end{array}\right] \mathrm{MPa} .}
\end{gathered}
$$

In Fig. $\mathrm{B} 1$, the $z$ coordinate and the $z_{k}-z_{k-1}$ dimension is shown for the thinner test probes.

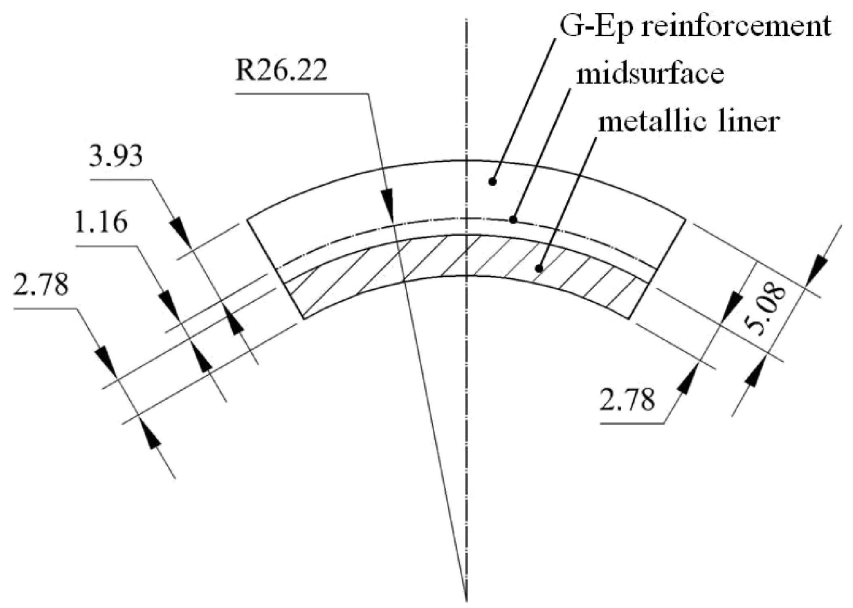

Fig. B1. Reinforced material set-up, dimensions are in mm

The extensional stiffness matrix $A_{i j}$ (in $\mathrm{N} / \mathrm{mm}$ ), the coupling stiffness matrix $B_{i j}$ (in $\mathrm{N}$ ), and the flexural stiffness matrix $D_{i j}$ (in $\mathrm{N} \mathrm{mm}$ ) of the RML of the thinner test probes are obtained using Eqs. (A4a) through (A4c):

$$
\begin{gathered}
{\left[A_{i j}\right]_{R M L}=\left[\begin{array}{ccc}
782 & 190 & 0 \\
190 & 634 & 0 \\
0 & 0 & 228
\end{array}\right] \times 10^{3},} \\
{\left[B_{i j}\right]_{R M L}=\left[\begin{array}{ccc}
-1.309 & -0.454 & 0 \\
-0.454 & -1.514 & 0 \\
0 & 0 & -0.543
\end{array}\right] \times 10^{6},} \\
{\left[D_{i j}\right]_{R M L}=\left[\begin{array}{ccc}
5.030 & 1.328 & 0 \\
1.328 & 4.428 & 0 \\
0 & 0 & 1.593
\end{array}\right] \times 10^{6} .}
\end{gathered}
$$

The computed values of the engineering constants $E_{H}^{o}, \nu_{H A}^{o}, E_{A}^{o}$, $\nu_{A H}^{o}$ in the middle-surface of both types of test probes are reported in Table 1 under columns 3 and 6, "Numerical".

Acknowledgements. Authors gratefully acknowledge Mr Felipe Parrilla Corzas and Mme Margarita López from Felipe Parrilla y Compañía SA de CV for the fabrication of the polymeric reinforcement; from IPN-ESIME Ticomán to Engs. Alfonso Espinosa Picazo, Gustavo Zamudio Rodriguez, and Gerardo López Ramírez for their tactical support, and Engs. Rubén Pardo Saavedra and Joaquín Cedillo Cárdenas for their administrative assistance; as well as Dr. David Hernández Silva from IPN-ESIQIE, and Dr. Orlando Susarrey Huerta from IPN-ESIME Zacatenco for making possible the experimental tasks; as well as to anonymous reviewers for their valuable comments and suggestions to improve the quality of this document.

\section{REFERENCES}

[1] K. Franzinger, Fluid Power 20/20, 09/01/2005, available at http://hydraulicspneumatics.com.

[2] F. Shen, "A filament-wound structure technology overview", Materials Chemistry and Physics 42, 96-100 (1995).

[3] I. Daniel and O. Ishai, Engineering Mechanics of Composite Materials, pp. 85-101, 142, 189, 244-246, Oxford University Press, New York, 1994.

[4] K. Sung and Y. Jae, "Effects of winding angles on throughthickness properties and residual strains of thick filament wound composite rings", Composites Science and Technology 65, 27-35 (2005). 
Approximate mechanical behavior analysis of a thick-wall metallic liner reinforced...

[5] Scot Industries Catalog 902, 19 (2015).

[6] D. Gay, Matériaux Composites, 4th edition, Éditions Hermes, Paris, 1997.

[7] E. Vargas-Rojas, "Mechanical characterization of metallic tubing reinforced with a composite material fabricated with filament-winding process", MSc Thesis, National Polytechnic Institute, Distrito Federal, 2007, (in Spanish).

[8] ASTM Standard D 2734 - 91, Void Content of Reinforced Plastics.

[9] ASTM Standard D 3800 - 79, (reapproved 1990), Density of High-Modulus Fibers.

[10] ASTM Standard D 792 - 91, Density and Specific Gravity (Relative Density) of Plastics by Displacement.

[11] ASTM Standard D 638 - 91, Tensile Properties of Plastics.

[12] ASTM Standard D 695 - 91, Test Method for Compressive Properties of Rigid Plastics.

[13] MIL-HDBK-17-3E Department of Defense Handbook, Polymer Matrix Composites, Materials Usage, Design and Analysis 3, 4-19-4-27 (1997).

[14] J.M. Berthelot, Matériaux Composites, Comportement Mécanique et Analyse des Structures, Éditions Technique et Documentation, Paris, 1999.
[15] R. Jones, Mechanics of Composite Materials, Taylor \& Francis, London, 1999.

[16] P.M. Schubel, J.J. Luo, and I.M. Daniel, "Through-thickness characterization of thick composite laminates", 2006 SEM Annual Conf. Exposition on Experimental and Applied Mechanics 1, CD-ROM (2006).

[17] L. Malvern, Introduction to the Mechanics of a Continuous Medium, Prentice-Hall, New Jersey, 1969.

[18] F. Gasquez, "Study of fully wound reservoirs aimed for hydrogen storage under pressure: type III case study", PhD Thesis, Université de Franche-Comté, Besançon, 2008, (in French).

[19] H. Hernández-Moreno, B. Douchin, F. Collombet, D. Choqueuse, and P. Davies, "Influence of winding pattern on the mechanical behavior of filament wound composite cylinders under external pressure", Composites Science and Technology 68, 1015-1024 (2008)

[20] H. Hernández-Moreno, "Fabrication monitoring of composite tubes manufactured by filament-winding and mechanical behavior under external pressure", $P h D$ Thesis, Université Paul Sabatier-Toulouse III, Toulouse, 2006, (in French).

[21] W. Flügge, Stress in Shells, 2nd edition, Springer-Verlag, Berlin, 1973. 